\title{
Mutations in the von Hippel-Lindau Tumour Suppressor Gene in Central Nervous System Hemangioblastomas
}

\author{
Cezary Cybulski', Joanna Matyjasik', Marianna Soroka², Janusz Szymaś3', Bohdan Górski', Tadeusz Dębniak', \\ Anna Jakubowska', Andrzej Bernaczyk ${ }^{4}$, Lech Zimnoch ${ }^{5}$, Grażyna Bierzyńska-Macyszyn ${ }^{6}$, Tomasz Trojanowski ${ }^{7}$, \\ Teresa Wierzba-Bobrowicz ${ }^{8}$, Edmund Prudlak', Alicja Markowska-Wojciechowska ${ }^{10}$, Przemysław Nowacki", \\ Andrzej Roszkiewicz ${ }^{12}$, Radzisław Kordek ${ }^{13}$, Tadeusz Szylberg ${ }^{14}$, Ewa Matyja ${ }^{15}$, Krzysztof Zieliński1 ${ }^{16}$, \\ Bogdan Woźniewicz ${ }^{17}$, Anna Taraszewska ${ }^{18}$, Wojciech Kozłowski ${ }^{19}$, Jan Lubiński'
}

\begin{abstract}
IInternational Hereditary Cancer Center, Department of Genetics and Pathology, Pomeranian Medical University, Szczecin, Poland; 2Department of Biology, University of Szczecin, Poland; ${ }^{3}$ Department of Clinical Pathology, Poznań University of Medical Sciences, Poland; ${ }^{4}$ Department of Pathology, Regional Clinical Hospital, Częstochowa, Poland; ${ }^{5}$ Department of Pathology, Medical University, Białystok, Poland; ${ }^{\circ D e p a r t m e n t ~ o f ~ P a t h o l o g y, ~ M e d i c a l ~ A c a d e m y, ~ K a t o w i c e, ~ P o l a n d ; ~}$ 7Department of Neurosurgery, University Medical School, Lublin, Poland; 8 Department of Neuropathology, Institute of Psychiatry and Neurology, Warsaw, Poland; 9Department of Pathology, Medical Academy, Wrocław, Poland; 10Department Otolaryngology, Medical Academy, Wrocław, Poland; "Department of Neurology, Pomeranian Medical University, Szczecin, Poland; 12Department of Pathology, Medical University of Gdańsk, Poland; 132Department of Pathology, Copernicus Memorial Hospital, tódź, Poland; ${ }^{14}$ Department of Pathomorphology, Military Clinical Hospital, Bydgoszcz, Poland; 15Department of Neuropathology, Medical Research Centre, Polish Academy of Sciences, Warsaw, Poland; 16Department of Pathology, Military Clinical Hospital, Kódź, Poland; 17Department of Pathomorphology, Children's Memorial Health Institute, Warsaw, Poland; ${ }^{18}$ Department of Neuropathology, Medical Research Centre, Polish Academy of Sciences, Warsaw, Poland; ${ }^{19}$ Department of Pathology, Military Clinical Hospital, Military Medical Academy, Warsaw, Poland
\end{abstract}

Key words: VHL disease, hemangioblastoma, germline mutations, VHL gene

Corresponding author: Cezary Cybulski, International Hereditary Cancer Center, Department of Genetics and Pathology, Pomeranian Medical University, Połabska 4, 70-115 Szczecin, Poland. Phone + 489146615 32, fax + 48914661533 , e-mail: cezarycy@sci.pam.szczecin.pl

Submitted: 15 January 2004

Accepted: 15 March 2004

\begin{abstract}
Central nervous system hemangioblastomas ( $\mathrm{CH} A \mathrm{~B}$ ) are rare tumours which most commonly arise in the cerebellum. Most tumours are sporadic, but as many as one third of cHABs occur in the course of the hereditary disorder - von Hippel-Lindau disease (VHL). In order to diagnose new VHL families in Poland we performed sequencing of the entire $\mathrm{VHL}$ gene in archival material (paraffin embedded hemangioblastoma tissues) in a large series of 203 unselected patients with cHAB. VHL gene mutations were detected in 70 $(41 \%)$ of 171 tumour samples from which DNA of relatively good quality was isolated. We were able to obtain blood samples from 19 of mutation positive cases. Eight (42\%) of these harboured germline mutations in persons from distinct undiagnosed VHL families.
\end{abstract}




\section{Introduction}

Central nervous system hemangioblastomas are rare tumours which most commonly arise in the cerebellum. Most tumours are sporadic, but as many as one third occur in the course of the hereditary disorder - von Hippel-Lindau disease (VHL) [1]. VHL disease is a rare autosomal dominant disorder characterized by a predisposition to hemangioblastomas of the central nervous system (cHAB) and retina, renal cell carcinomas and pheochromocytomas. The predisposition is caused by germline mutations in the VHL tumour suppressor gene on chromosome 3p25-26 [2]. Germline mutations in the VHL gene are present in almost all VHL families $[3,4]$. From a clinical perspective it is very important to distinguish between sporadic and VHL-associated hemangioblastomas because of the risk of early onset and multiple organ tumours in VHL families. Early diagnosis of $\mathrm{VHL}$ disease allows for the proper management of not only hemangioblastomas but of other VHL-related lesions as well. Clinical screening according to a carefully planned surveillance schedule results in an improved prognosis for VHL subjects [5].

Given the occurrence of $\mathrm{VHL}$ disease with a frequency of 1:36 000 live births, it is estimated that there are as many as $1000 \mathrm{VHL}$ patients in Poland. However, to date, the Polish VHL Registry includes only about $100 \mathrm{VHL}$ patients from 34 Polish families [4]. Thus, in order to diagnose new VHL families in Poland, we performed sequencing of the entire $\mathrm{VHL}$ gene in all available archival material (paraffin embedded $\mathrm{CHAB}$ tissues) from a series of 203 unselected patients with $\mathrm{CHAB}$ diagnosed in Poland primarily in the period between 1999 and 2003.

\section{Material and methods}

Tissues embedded in paraffin blocks were collected from 203 cHAB patients operated in different Medical Centres in Poland. Most patients were operated between 1999 and 2003, but some of them were diagnosed prior to 1999 (Poznań, Kraków). Paraffin blocks were obtained from 7 neuropathology departments (Szczecin, Poznań, Lublin, Warszawa, Katowice, Wrocław, Częstochowa). Cases were unselected for age, clinical presentation or family history.

DNA isolation was performed as described previously [6]. In brief, formalin fixed, paraffin embedded tissues were sectioned into slides, then deparaffinized in two changes of xylene. Sections were hydrated through a series of graded alcohols. Tissues were placed in $1.5 \mathrm{ml}$ eppendorf tubes and digested with proteinase K. After digestion, proteinase was heat inactivated. After purification in Microcon-100 tubes (Amicon), a solution containing DNA was diluted in $50 \mu \mathrm{dH} 2 \mathrm{O}$.

The entire coding sequence of the $\mathrm{VHL}$ gene was amplified in nested PCR using 6 pairs of primers (available on request). In brief, 3 exons of the $\mathrm{VHL}$ gene were initially amplified in 25 cycles each of $95^{\circ} \mathrm{C} 30$ s, $60^{\circ} \mathrm{C} 30 \mathrm{~s}, 72^{\circ} \mathrm{C} 30$ s with external primers. Then, reamplified with internal primers in 25 PCR cycles using the same conditions. Negative controls were used to avoid false results. After purification, PCR products were sequenced with the internal primers, using fluorescently labelled dideoxy chain terminators from an ABI Prism kit (Applied Biosystems) in an ABI 377 automated sequencer.

\section{Results}

Amplification of the coding sequence of the $\mathrm{VHL}$ gene was successful in 171 of 203 cHAB samples. Automated sequencing showed $\mathrm{VHL}$ gene mutations in 70 (41\%) of 171 tumours (Table 1). Single VHL changes were identified in 67 tumours. In the remaining 3 tumours two different VHL mutations were identified.

Altogether 52 different VHL changes were identified. Forty eight mutations were observed in single hemangioblastoma cases. The following four mutations were recurrent: $233 \mathrm{~A}>\mathrm{G}$ was detected in 4 cases, $239 \mathrm{G}>\mathrm{A}$ present in 2 cases, 266T $>$ A observed in 2 cases, and IVS3-1G>T identified in 17 cases. All changes except one silent variant (Ala50Ala) resulted in alteration of $\mathrm{VHL}$ protein sequence.

Intragenic VHL mutations were non-randomly distributed, all changes (except one silent variant) were localized downstream codon 53. Of the 171 tumours, $36(21 \%)$ had mutations within exon 1, 9 (5\%) within exon 2 , and $5(3 \%)$ within exon 3 . In addition to these mutations in the coding sequence we identified one of four splice site mutations in 20 (28\%) tumours (IVS 1 + 1G >A, IVS2 + 2T >C, IVS2 + 2T>G in single cases and IVS3-1G $>T$ in 17 tumours).

We were able to obtain blood samples from 19 of the 70 mutation positive cases. Eight (42\%) of these harboured germline mutations and eleven (58\%) had somatic mutations present only in their tumours, but not in peripheral blood leukocytes.

\section{Discussion}

We identified mutations of the VHL gene in 70 (41\%) of unselected hemangioblastoma tumours. Our results are in line with previous smaller studies showing that $\mathrm{VHL}$ gene mutation is a critical event in the pathogenesis of both familial and sporadic hemangioblastoma [7-13]. 
Table 1. VHL gene mutations in hemangioblastoma of the central nervous system

\begin{tabular}{|c|c|c|c|c|c|c|c|}
\hline Case & Mutation & Consequence & Character & 28 & $266 \mathrm{~T}>\mathrm{A}$ & Leu89His & Uv \\
\hline \multicolumn{4}{|c|}{ exon 1} & 29 & $266 \mathrm{~T}>\mathrm{A}$ & Leu89His & Somatic mutation \\
\hline 1 & $150 C>T$ & Ala50Ala & $U_{v}$ & \multirow[t]{2}{*}{30} & $266 \mathrm{~T}>\mathrm{C}$ & Leu89Pro & Somatic mutation \\
\hline \multirow{2}{*}{2} & \multirow{2}{*}{$163 G>A$} & \multirow{2}{*}{ Glu55Lys } & \multirow{2}{*}{ Uv } & & $194 \mathrm{C}>\mathrm{T}$ & Ser65Leu & Germline mutation \\
\hline & & & & 31 & $266 \mathrm{~T}>\mathrm{G}$ & Leu89Arg & Uv \\
\hline 3 & $170 G>C$ & Gly57Ala & Uv & 32 & $268 \mathrm{~A}>\mathrm{T}$ & Asn90Tyr & $U_{v}$ \\
\hline \multirow[t]{2}{*}{4} & $173 G>A$ & \multirow[t]{2}{*}{ Arg58Gln } & \multirow[t]{2}{*}{ Uv } & & & & \\
\hline & \multirow{2}{*}{ 174del149 } & & & 33 & $275 A>G$ & Asp92Gln & Uv \\
\hline 5 & & In frame & Somatic mutation & \multirow{2}{*}{34} & \multirow{2}{*}{$\begin{array}{l}334 \mathrm{~T}>\mathrm{C} \\
254 \text { del} 54\end{array}$} & \multirow{2}{*}{$\begin{array}{l}\text { Tyr } 112 \mathrm{His} \\
\text { In frame }\end{array}$} & \multirow[t]{2}{*}{ Somatic mutations } \\
\hline 6 & $184 G>A$ & Val62Met & Uv & & & & \\
\hline 7 & $193 \mathrm{~T}>\mathrm{C}$ & Ser65Pro & Germline mutation & 35 & $338 \mathrm{G}>\mathrm{A}$ & $\operatorname{Arg} 113 \mathrm{Gln}$ & Uv \\
\hline 8 & $194 C>G$ & Ser65Trp & Uv & 36 & $340 G>C$ & Gly1 14Arg & Uv \\
\hline 9 & $196 \mathrm{G}>\mathrm{A}$ & Val66Met & Uv & 37 & $\operatorname{IVS} 1+1 \mathrm{G}>\mathrm{A}$ & Splice & Germline mutation \\
\hline 10 & 206insG & Frameshift & Somatic mutation & & & exon2 & \\
\hline \multirow[t]{2}{*}{11} & \multirow{2}{*}{$\begin{array}{l}218 A>G \\
302 T>C\end{array}$} & \multirow{2}{*}{$\begin{array}{l}\text { Gln73Arg } \\
\text { Leu } 101 \text { Pro }\end{array}$} & \multirow[t]{2}{*}{ Uv } & 38 & $353 \mathrm{~T}>\mathrm{C}$ & leul18pro & Uv \\
\hline & & & & 39 & 357delC & Frameshift & Somatic mutation \\
\hline 12 & $220 G>A$ & Val74lle & Uv & 40 & 363delT & Frameshift & Uv \\
\hline 13 & $227 \mathrm{~T}>\mathrm{A}$ & Phe76Tyr & Uv & 41 & $379 G>A$ & Gly127Arg & Uv \\
\hline 14 & $227 \mathrm{~T}>\mathrm{C}$ & Phe76Ser & Uv & 42 & $382 C>T$ & Leu128Phe & Uv \\
\hline 15 & $232 A>G$ & Asn78Asp & Somatic mutation & 43 & $403 \mathrm{~T}>\mathrm{A}$ & Leu135lle & $U_{v}$ \\
\hline 16 & $233 A>G$ & Asn78Ser & Germline mutation & 44 & 437delC & Frameshift & $U_{v}$ \\
\hline 17 & $233 A>G$ & Asn78Ser & Uv & 45 & $463 G>T$ & Val155Leu & $U_{v}$ \\
\hline 18 & $233 A>G$ & Asn78Ser & Uv & 46 & $463 G>A$ & Val155Met & Germline mutation \\
\hline 19 & $233 A>G$ & Asn78Ser & Uv & 47 & $\mathrm{IVS} 2+2 \mathrm{~T}>\mathrm{C}$ & Splice & $U_{v}$ \\
\hline 20 & $239 G>A$ & Ser80Asn & Uv & 48 & $\mathrm{IVS} 2+2 \mathrm{~T}>\mathrm{G}$ & Splice & $U_{v}$ \\
\hline 21 & $239 G>A$ & Ser80Asn & Uv & & & exon3 & \\
\hline 22 & $240 T>G$ & Ser80Arg & Uv & 49 & 474 delG & Frameshift & $U_{v}$ \\
\hline 23 & $250 G>A$ & Val84Met & Uv & 50 & 477-478insCA & Frameshift & Germline mutation \\
\hline 24 & $254 \mathrm{~T}>\mathrm{C}$ & Leu85Pro & Uv & 51 & $481 C>T$ & $\operatorname{Arg} 161 x$ & Germline mutation \\
\hline 25 & $257 C>T$ & Pro86Leu & Uv & 52 & $486 C>G$ & Cys 162Trp & $U_{v}$ \\
\hline 26 & 259delTAT & In frame & Uv & 53 & $499 C>T$ & Arg 167Trp & Germline mutation \\
\hline 27 & $263 G>A$ & Trp88X & Somatic mutation & $54-7$ & 70 IVS3-1G>T* & Splice & Somatic mutation? \\
\hline
\end{tabular}

Germline mutation - mutation detected in DNA from tumour and from peripheral blood leukocytes

Somatic mutation - mutation present in tumour but not in peripheral blood leukocytes

Uv - unverified variant (detected in tumour - blood sample not tested)

* - mutation present in tumour tissue, but not detected in DNA isolated from blood leukocytes of four available cases - probably somatic mutation 
Previous investigations demonstrated that the VHL gene acts as a classic tumour suppressor gene for sporadic and VHL-related hemangioblastomas (and also renal cell carcinoma, pheochromocytoma and pancreatic tumours), as inactivation of both VHL alleles either by point mutations, loss of the entire allele or $\mathrm{VHL}$ promoter methylation has been shown in these tumours [7-13]. Although we did not investigate such somatic events as loss of heterozygosity or promoter methylation, in one case (no. 34) we identified two different point mutations and demonstrated that the two somatic events affected both $\mathrm{VHL}$ alleles. This is an interesting and rare example of $\mathrm{VHL}$ gene inactivation by two somatic point mutations in hemangioblastoma. Also, tumours no. 11 and 30 harboured two different small intragenic mutations, however we did not verify whether the mutations affected both $\mathrm{VHL}$ alleles.

In the present study we detected 52 different $\mathrm{VHL}$ changes. We observed different types of $\mathrm{VHL}$ mutations (missense, nonsense, in-frame and frameshift deletions and insertions, and splice site alterations), localized in all exons of the VHL gene and downstream codon 53. DNA alterations (including missense variants) localized 3' of codon 53 (highly conserved region of the VHL gene) are predicted to be true mutations [15], thus all $\mathrm{VHL}$ changes (except one silent variant) reported in this series are believed to be pathogenic.

In the current series, most mutations were observed in single cases. Only the IVS3-1 G>T splice site mutation was relatively common (identified in 17 cases). This variant was present in tumour tissue, but it was not detected in DNA isolated from blood leukocytes of four patients. Thus, it seems that the IVS3-1G>T mutation may be a somatic event relatively common in hemangioblastoma. However, in the remaining cases, the germline character of the IVS3-1G>T mutation cannot be excluded.

The incidence of $\mathrm{VHL}$ disease among $\mathrm{CHAB}$ patients is between $5 \%$ and $30 \%[16,17]$. More recent reports describe an incidence of about $40 \%[18,19]$ and suggest that $\mathrm{VHL}$ disease was underdiagnosed prior to the introduction of modern imaging techniques and molecular analysis of the $\mathrm{VHL}$ gene. In regards to the $41 \%$ prevalence of small intragenic mutations in our group of 171 cHAB patients, and that approximately $42 \%$ of these mutations are germline (of the 19 mutation positive hemangioblastoma tumours from whom blood samples were available, eight (42\%) harboured germline mutations), we calculate that VHL disease caused by intragenic mutations occurs in about $17 \%$ of unselected hemangioblastoma patients in Poland. Given that the sensitivity of direct sequencing is about $60 \%$ in the diagnosis of VHL disease in the Polish population [4], we estimate that $\mathrm{VHL}$ disease is present in about $25 \%$ of unselected patients with $\mathrm{CHAB}$ in Poland.

We believe that the most efficient way of diagnosis of $\mathrm{VHL}$ is to provide genetic counselling to all VHL suspected patients at the time of diagnosis of $\mathrm{VHL}$-associated lesions. In this study we showed that the analysis of archival material from paraffin sections is relatively efficient in searching for new VHL cases, when DNA from peripheral blood is not available. Using this approach, we diagnosed eight novel VHL families in Poland and offered appropriate surveillance and treatment of disease to these families.

\section{References}

1. Neumann HP, Lips CJ, Hsia YE and Zbar B. Von Hippel-Lindau syndrome. Brain Pathol 1995; 5: $181-193$

2. Maher ER and Kaelin WG, Jr. Von Hippel-Lindau disease. Medicine (Baltimore) 1997; 76: 381-391.

3. Stolle C, Glenn G, Zbar B, Humphey JS, Choyke P, Walther M, Pack S, Hurley K, Andrey C, Klausner R and Linehan WM. Improved detection of germline mutations in the von Hippel-Lindau disease tumor suppressor gene. Hum Mutat 1998; 12: $417-423$.

4. Cybulski C, Krzystolik K, Murgia A, Gorski B, Debniak T, Jakubowska A, Martella M, Kurzawski G, Prost M, Kojder I, Limon J, Nowacki P, Sagan L, Bialas B, Kaluza J, Zdunek M, Omulecka A, Jaskolski D, Kostyk E, Koraszewska-Matuszewska B, Haus $O$, Janiszewska H, Pecold K, Starzycka M, Slomski R, Cwirko M, Sikorski A, Gliniewicz B, Cyrylowski L, Fiszer-Maliszewska L, Gronwald J, Toloczko-Grabarek A, Zajączek S and Lubinski J. Germline mutations in the von Hippel-Lindau (VHL) gene in patients from Poland: disease presentation in patients with deletions of the entire VHL gene. J Med Genet 2002; 39 (7): E38.

5. Maddock IR, Moran A, Maher ER, Teare MD, Norman A, Payne SJ, Whitehouse R, Dodd C, Lavin M, Hartley N, Super M and Evans DG. A genetic register for von Hippel-Lindau disease. J Med Genet 1996; 33: 120-127.

6. Cybulski C, Gorski B, Debniak T, Gliniewicz B, Mierzejewski M, Masojc B, Jakubowska A, Matyjasik J, Złowocka E, Sikorski A, Narod SA and Lubiński J. NBS1 is a prostate cancer susceptibility gene. Cancer Res 2004; 64 (4): 1215-1219.

7. Kanno H, Kondo K, Ito S, Yamamoto I, Fujii S, Torigoe S, Sakai N, Hosaka M, Shuin T and Yao M. Somatic mutations of the von Hippel-Lindau tumour suppressor gene in sporadic central nervous system hemangioblastomas. Cancer Res 1994; 54 : 4845-4847.

8. Oberstrass J, Reifenberger G, Reifenberger J, Wechsler W and Collins VP. Mutation of the Von Hippel-Lindau tumour suppressor gene in capillary haemangioblastomas of the central nervous system. J Pathol 1996; 179: 151-156.

9. Tse JY, Wong JH, Lo KW, Poon WS, Huang DP and Ng HK. Molecular genetic analysis of the von Hippel-Lindau disease tumour suppressor gene in familial and sporadic cerebellar hemangioblastomas. Am J Clin Pathol 1997; 107: 459-466.

10. Vortmeyer AO, Gnarra JR, Emmert-Buck MR, Katz D, Linehan WM, Oldfield EH and Zhuang Z. Von Hippel-Lindau gene deletion detected in the stromal cell component of a cerebellar hemangioblastoma associated with von Hippel-Lindau disease. Hum Pathol 1997; 28: 540-543.

11. Lee JY, Dong SM, Park WS, Yoo NJ, Kim CS, Jang JJ, Chi JG, Zbar B, Lubensky IA, Linehan WM, Vortmeyer AO and Zhuang 
Z. Loss of heterozygosity and somatic mutations of the VHL tumour suppressor gene in sporadic cerebellar hemangioblastomas. Cancer Res 1998; 58: 504-508.

12. Crossey PA, Foster K, Richards FM, Phipps ME, Latif F, Tory K, Jones MH, Bentley E, Kumar R, Lerman Ml, et al. Molecular genetic investigations of the mechanism of tumourigenesis in von Hippel-Lindau disease: analysis of allele loss in VHL tumours. Hum Genet 1994; 93: 53-8.

13. Prowse AH, Webster AR, Richards FM, Richard S, Olschwang S, Resche F, Affara NA and Maher ER. Somatic inactivation of the VHL gene in Von Hippel-Lindau disease tumours. Am J Hum Genet 1997; 60: 765-771.

14. Glasker S, Bender BU, Apel TW, van Velthoven V, Mulligan LM, Zentner J and Neumann HP. Reconsideration of biallelic inactivation of the $\mathrm{VHL}$ tumour suppressor gene in hemangioblastomas of the central nervous system. J Neurol Neurosurg Psychiatry 2001; 70 (5): 644-648.

15. Stebbins CE, Kaelin WG Jr and Pavletich NP. Structure of the $\mathrm{VHL}$-ElonginC-ElonginB complex: implications for $\mathrm{VHL}$ tumor suppressor function. Science 1999; 284 (5413): 455-461.

16. Maher ER, Yates JR, Harries R, Benjamin C, Harris R, Moore AT and Ferguson-Smith MA. Clinical features and natural history of von Hippel-Lindau disease. Q J Med 1990; 77; 1151-1163.

17. Sung DI, Chang $\mathrm{CH}$ and Harisiadis L. Cerebellar hemangioblastomas. Cancer 1982; 49: 553-555.

18. Sora S, Ueki K, Saito N, Kawahara N, Shitara N and Kirino T. Incidence of von Hippel-Lindau disease in hemangioblastoma patients: the University of Tokyo Hospital experience from 1954. 1998. Acta Neurochir (Wien) 2001; 143 (9): 893-896.

19. Richard S, David P, Marsot-Dupuch K, Giraud S, Beroud C and Resche F. Central nervous system hemangioblastomas, endolymphatic sac tumors, and von Hippel-Lindau disease. Neurosurg Rev 2000; 23 (1): 1-22; discussion 23-4. 